\title{
ALL CAUGHT UP IN THE KAYFABE Understanding and Appreciating Pro-Wrestling
}

Lisa Jones

Professional wrestling is a popular, global, performance phenomenon that is in many respects sport-like, but tends to be shunned by serious sports fans for its alleged 'fakeness'. Yet its own fans often behave exactly like regular sports fans: getting caught up in the action, responding emotionally to the performances, and engaging in critical analysis of the competitive strategies and the turns of events. How does this alleged 'fake sport' engender such complex and deeply emotional appreciation? Here I provide an analysis of pro-wrestling that explains and emphasises its narrative, dramatic and fictional aspects, showing it to be a complex representational work that can be appreciated aesthetically and emotionally on a number of levels.

KEYWORDS: Professional wrestling, fiction, fictional worlds, kayfabe, make-believe, spectacle, appreciation.

\section{Introduction}

Pro-wrestling - the flamboyant, popular form of sports entertainment watched by millions around the globe-occupies a somewhat strange place in the landscape of appreciation. ${ }^{1}$ Serious sports fans tend to shun it, citing its alleged 'fakeness' as a reason not to engage with it, and an admission that one is a fan of pro-wrestling often draws a puzzled look from others, as if it can't quite be taken seriously. And indeed, pro-wrestling is not, strictly speaking, a sport (though its relationship to sport is in some respects a close one). Nonetheless, wrestling fans often behave very much like regular sports fans - in the arenas they cheer and jeer, leap from their seats, scream their hearts out, clutch their heads or throw their 
hands up, in just the same way that spectators at a football game or a boxing match might. ${ }^{2}$ Even when just watching through the medium of television in their own homes, fans may still exhibit much of the same behaviour, if a little less exuberantly. Initially, this seems puzzling, given that pro-wrestling is not 'proper sport' - what are the fans getting so excited about? How can they be so moved by something so fake?

The apparent puzzle, however, arises only due to the misconception that pro-wrestling is 'fake sport'. As soon as we correct that and see pro-wrestling for what it really is, there is no surprise as to why its fans or audiences behave the way they do. In fact, a close and careful look at the phenomenon of pro-wrestling reveals that it arguably makes more sense for these fans to be passionate about this form of entertainment than it does for 'real' sports fans to be moved by and engaged in the fortunes of their teams; it also reveals that the nature of pro-wrestling fans' engagement with the phenomenon is complex, layered, and sophisticated, while being grounded in a fundamental human practice.

In what follows, I shall first offer an explanation of what kind of phenomenon pro-wrestling is, which will make salient the kind of appreciation it warrants. Then I shall discuss in more detail the layers of appreciation and engagement that prowrestling invites, from its basic sensory delights through to its more profound dramatic themes, its invitation to complex imaginative play, and its opportunities for interactivity. In providing this comprehensive account, I shall show that what pro-wrestling fans are doing when they engage with their pastime is participating in a fundamentally human imaginative activity that is richly rewarding and bears a good deal of aesthetic value.

\section{But You Know It's Fake, Right?}

Let us take as our starting point the allegation that pro-wrestling is 'fake'. This allegation is perhaps the most common reaction pro-wrestling fans receive when they reveal that they follow pro-wrestling. The thought would seem to be that the adjective 'fake' is apt since pro-wrestling presents itself as a sport, and yet the outcomes of its matches are pre-determined and its in-ring action is largely choreographed. Since 'real' sport is genuinely competitive - that is, it consists in a genuine contest over who wins and who loses, and this outcome is determined in 
the course of the sports activity or game, and not before - then pro-wrestling, with its pre-determined outcomes and choreographed activity, is mere 'faking'. 3

These characterisations of how pro-wrestling works are correct. Prowrestling is, in the commonly-used parlance, scripted. Its in-ring wrestling bouts are indeed planned, both in terms of who will win and lose and roughly how the match will unfold; the moves that make up the match will be loosely choreographed, and some might be rehearsed. Moreover, this scripting goes beyond individual matches to encompass the wider trajectories of each wrestler - the stories of who wins, who loses, who is the underdog and who is the rising star, who becomes champion and who remains a mid-card contender - all of these trajectories are planned and written by a team of 'creatives' working behind the scenes. And in playing out these trajectories, wrestlers not only wrestle, but also perform in-ring or backstage promos - promotional pieces to camera that provide dramatic impetus and that are also, of course, scripted (to a greater or lesser degree). This is all true. But what of it? It would only be a problem - one deserving of the pejorative adjective 'fake' - if pro-wrestling were indeed claiming to be, or presenting itself deceitfully as, a genuine competitive sport. But this is patently not the case. While the origins of today's pro-wrestling may have been shadier, carnival sideshow stings involving the exploitation of gullible audiences, this is no longer how things are, nor how they have been for some time. Pro-wrestling does not in fact present itself as 'real' sport and, moreover, makes it abundantly clear that it does not - so clear, in fact, that it is perennially surprising that wrestling-sceptics should get it so wrong.

Wrestlers are openly referred to as 'characters' or 'actors'. ${ }^{4}$ The acting that they enact is invariably delivered in an over-the-top, camp style that leaves viewers in no doubt that what they are watching is scripted. Anyone who even just scratches the surface of pro-wrestling grasps immediately that there is a fictional world operating here - a world whose events are presented to us in the fictive mode, i.e. with the intention that we adopt a fictive stance towards them. There is even a dedicated term for this fictional aspect, in wrestling parlance - it is referred to as the kayfabe. And the fundamental conceit of the kayfabe is the pretence that the in-ring and back-stage performances are genuine, that they are legitimate feuds and wrestled fights, when in fact they are a matter of fictive performance. I will have 
much more to say about the mechanics of this fictional world in what follows; for now, all we need is to grasp that pro-wrestling is a kind of theatre with which audiences and fans knowingly engage. Audiences of pro-wrestling know that they are not watching a 'real' sport. They know they are not watching competitors actually engaged in conflict - what they are watching is the fictional representation of sporting conflict. It is perhaps only small children who would take pro-wrestling to be 'real', in the same way that they might think Santa Claus is real - until they grow out of that belief and understand it for the fiction that it is.

It is worth remarking that, while pro-wrestling is not 'real sport', there is still much that is sport-like about it. A label often used to categorise pro-wrestling is that of 'sports entertainment', and this seems apt so long as we understand the term 'sports' here as an adjectival qualification of the noun 'entertainment'. This is justified partly because of the central fictional conceit that the wrestling activity is real sporting contest, and partly because of the actual athletic physicality of the phenomenon. The in-ring stars of pro-wrestling may be described as actors or entertainers, but they are also undoubtedly athletes - they are extremely fit, highly trained, and disciplined. Since they put their bodies through extreme physical trials on a regular basis, they are also liable to injuries just like sportspersons and other physical performers, such as dancers. Moreover, their discipline is most certainly a craft - it takes a good deal skill to perform wrestling, not only in terms of learning how to perform the in-ring moves, and how to 'sell' them (that is, perform them in a way that contributes to the fictional conceit that they are 'really' combative), but also in terms of doing all of this while not actually injuring one's opponents, and while maintaining a theatrical performance style that is responsive to the watching crowds. Professional wrestlers must be both accomplished athletes and prodigious showpersons. All told, this requires a considerable set of skills that can take years to hone.

It should now be clear, then, that it is a misperception to view pro-wrestling as a deceitfully fake sport. It is, rather, a scripted, athletic mode of storytelling that takes place within a fictional world featuring characters who get into conflicts with one another, compete for titles, and enact pre-determined fighting bouts that may be semi-choreographed but are no less physical, athletic or skilful for having being 
scripted. Understanding pro-wrestling as such, it is immediately easier to see why fans and audiences might engage with it - they might do so, for example, for similar reasons that people go to the theatre, or watch televised drama. They might do so for the sake of the goods one generally gets from engaging with performed dramatic narratives - namely, aesthetic, emotional, and cognitive goods. And the form their appreciation takes will be similar to the form of our appreciation for other dramatic narrative performances - similar, though with some particular aspects that are arguably unique to pro-wrestling. These goods of engagement and modes of appreciation will be explored in the following sections.

\section{What Did We Just Witness? Soap Opera, Spectacle and Signs}

Engagement with and appreciation of pro-wrestling occurs on a variety of levels, just as with other narrative and performative fictional art forms. At a simple level, there is the sheer aesthetic pleasure to be had from the physical and visual aspects of the performances and wrestling shows. This includes both the enjoyment of the spectacular and flamboyant showmanship element, on the one handinvolving costumes, lights, pyrotechnics and music - and, on the other hand, the exhilarating bodily performances of the wrestlers themselves as they leap and fly around the ring, executing their practised and choreographed moves. There is an element of beauty and grace to be found in a well-executed slingblade, moonsault, or super-plex, to name just a few established wrestling moves, and audiences are occasionally wowed simply by the physical achievements of the performers. Some moves are just beautiful to watch, as is true in many real sports - though in the case of real sports, the beauty of a move tends to be incidental to its function and intended effect. The beauty in wrestling moves, by contrast, is actually part of the function of the moves, which is to represent combat in an artistic, athletic manner; it is therefore perhaps more comparable to the beauty arising from dance, where representation, expression and pleasing formal arrangement are purposely combined.

The visual and physical aspects, then, generate a surface aesthetic pleasure that audiences can enjoy. But this is not all they do; they are of course also the basic vehicle for the narrative and dramatic elements that are perhaps the beating heart 
of pro-wrestling. In the wrestling ring, and out of it, stories are told. Individual fighting bouts are set within broader contexts of ongoing feuds or other narratives, wherein the fighting bouts themselves are connected, fleshed out and enhanced by promos. The stories thus extend beyond both the confines of the ring and the duration of the matches, and it is not just possible but in fact common for some storylines to continue over several years. Given this longer-form storytelling, it may well be apposite to consider pro-wrestling as akin to soap opera-indeed, one of the labels it has been given over the years is 'soap opera for men'. The soap-operatic element consists in the ongoing, open-ended stories of the various individual wrestlers' attempts to make their way up in the world of wrestling, their fates rising and falling, with feuds emerging, developing, and working towards closure before beginning anew.

This is an absorbing dramatic context, even if the drama is, admittedly, somewhat simplistic in its basic outlines. The storytelling relies on a basic dynamic of good versus evil - or, in wrestling terms, 'babyfaces' (aka 'faces') versus 'heels' from which narrative arcs are developed. These narratives often instantiate quest plots, where characters fight their way up from obscurity to championship, overcoming obstacles and enemies on the way; and they may often involve reversals, where characters who start off good turn bad (the villainous 'heel turn'), and vice versa (the 'face turn'). Such perennial stories are told over and again, in each generation of wrestlers.

While these kinds of basic storylines may make pro-wrestling somewhat simplistic in plot terms - perhaps more so than actual soap operas, and certainly more so than serious drama - this does not mean that pro-wrestling lacks the power to draw an audience in, and enthral them. Sophistication of plot is not the only measure of the appeal of narrative drama. There are two additional features of good, classic drama that are present to a considerable degree in pro-wrestling, and that render it a more complex appreciative kind. These are its spectacular form, and its profound themes.

Let us consider first the manner in which wrestling narratives are told or, rather, shown. Pro-wrestling is played out on a vast live stage, before thousands of spectators, and is tailored specifically to this kind of setting. 5 In this respect, as a 
form of theatre it is perhaps closer to ancient Greek drama than to modern drama; it is - to use the terminology preferred by Roland Barthes - a kind of spectacle (Barthes: 1957). ${ }^{6}$ In his essay, Barthes was primarily concerned with the semiotics of pro-wrestling, but in addition to highlighting the signs that can be read in its practices he also makes a number of insightful claims about its artistic nature and value. Most significantly, he identifies it as spectacle - a particular form of drama that operates via grand gestures to convey profoundly human themes. Wrestling is, he says $(1957,13)$, 'a spectacle of excess' in which 'we find a grandiloquence which must have been that of the ancient theatres'.

Understanding pro-wrestling as this specific type of narrative drama spectacle-makes a crucial difference, in that it leads us to re-evaluate what we may have first thought was an unsophisticated, hammy level of dramatic acting. Wrestlers might to our modern eyes appear to be poor actors, over-egging things considerably, to the point where it seems cringeworthy, until we realise that their art is the art of spectacle, not of ordinary modern drama. Their art is one that 'derives its originality from all the excesses which make it a spectacle and not a sport'. (Barthes: 1957, 21). Their performances, far from being hammy and over-thetop as they would be in an ordinary theatre, aim at a different kind of target and scale - that of the arena, where every sign must be clear so as to be understood immediately:

The gesture of the vanquished wrestler signifying to the world a defeat which, far from disguising, he emphasises and holds like a pause in music, corresponds to the mask of antiquity meant to signify the tragic mode of the spectacle. In wrestling, as on the stage in antiquity, one is not ashamed of one's suffering, one knows how to cry, one has a liking for tears. (Barthes: 1957, 14).

Understanding the visual behaviours of the wrestlers as part of a tradition of spectacle gives us a different take on their mode and methods of performance, and enables us to grasp that these performances are deliberate expressions of deep, human themes. That is, the grandiloquent gestures of the wrestler function to make salient to the audience certain core notions of profound human interest. As Barthes (1957, 17-18) says: 
[w] hat is thus displayed for the public is the great spectacle of Suffering, Defeat, and Justice. Wrestling presents man's suffering with all the amplification of tragic masks. The wrestler who suffers in a hold which is reputedly cruel (an arm-lock, a twisted leg) offers an excessive portrayal of Suffering; like a primitive Pieta, he exhibits for all to see his face, exaggeratedly contorted by an intolerable affliction. It is obvious, of course, that in wrestling reserve would be out of place, since it is opposed to the voluntary ostentation of the spectacle, to this Exhibition of Suffering which is the very aim of the fight. ... [F]or everyone must not only see that the man suffers, but also and above all understand why he suffers.

Suffering, defeat, and justice - themes that would have been familiar to the audiences of ancient spectacle, and that are no less recognisable to contemporary audiences of pro-wrestling. What compels the wrestling fan to follow every move of the choreographed match and respond to each heightened moment is the fact that these moments and these gestures signify themes that the audience can recognise as woven into their own ordinary lives. When a babyface wrestler suffers adversity and defeat, the audience can relate to this on some level. The slings and arrows of the misfortunes of people's everyday lives are writ large upon the stage of the prowrestling ring, and witnessing them provides moments of catharsis for the wrestling fan, just as witnessing the sorrows and tragedy of ancient spectacle did for the ancients. ${ }^{7}$ And for Barthes $(1957,19)$ the most important of these themes, 'what wrestling is above all meant to portray ... is that of justice'.

That justice should be the core theme is no surprise, given the basic storylines of good versus evil that pro-wrestling presents. In the eternal battles between babyfaces and heels, the villainous heels are more often than not the victors, usually as a result of obvious foul play or cheating. This creates an imbalance in the world, and generates a keen desire on the part of the audience for justice to be served, for the villain to get his, or her, comeuppance. Inevitably, the satisfaction of this desire in the wrestling story will - as so often in life - be continually deferred, much to the audience's dismay; but eventually, they - and the wronged babyface character - will be given what they clamour for. 
The idea that wrestling is, above all, about justice is echoed by other wrestling critics and aficionados too, such as the small-time wrestler Babyface Cauliflower Brown, who is the subject of a New York Times film essay (Grant, 2017). In that film, he discloses: '[t]here is a story that gets told in wrestling about how things ought to be. It's a story about getting the redemption we feel we deserve. That's a story that every form of art, and every type of storytelling has tried to tell'.

Pro-wrestling, then, can be seen as part of a tradition of storytelling art that precedes modern forms of dramatic storytelling. Pro-wrestling's mode of storytelling is one in which exaggerated signs make clear to us the significance of what the characters are going through, and invite us to empathise with the suffering, defeat, betrayal, and revenge being played out in the ring, and finally to take pleasure in the eventual appearance of justice. This provides justification for the thought that there is considerable aesthetic value to be had in engaging with the athletic mode of storytelling that is pro-wrestling, for even if the narratives themselves are at heart simple plots of good and evil, they carry themes embodying profound aspects of human experience. These themes, represented or displayed for the audience in a manner that is lavish and immediate, call forth emotional responses and ultimately cathartic effects on the part of the audience, resulting in the kind of serious aesthetic pleasure that other - more 'reputable' - narrative and dramatic artforms tend to give us.

But all of this can only happen if the audience is drawn into the fictional world effectively, in the first place. In the following section I explore the mechanics of this fiction, to show why pro-wrestling counts as a unique instance of fictional engagement.

\section{Caught Up In The Kayfabe: The Power Of Make-Believe}

It has already been said that pro-wrestling is a form of theatre that audiences knowingly engage with, involving performances constituting an athletic mode of storytelling while representing actions and events that are understood to take place within a fictional world. In some respects, then, we engage with pro-wrestling much as we do when we read a novel, watch a movie, or attend a play. But in other respects, the fictional engagement with pro-wrestling differs in important ways 
from the other fictions with which we are familiar. It is arguably both more immersive, and more interactive.

By 'more immersive', I mean that the distance usually maintained between ourselves and the fiction in the case of, say, novels, films, and plays, is vastly reduced in the case of pro-wrestling. Even when compared with its closest neighbouring fictional form, theatre, the difference is marked. In theatre, we also watch actors perform live before us and tell stories through their actions, but with theatre we ourselves are not traditionally part of the performance - we are behind the so-called fourth wall. ${ }^{8}$ The actors on stage do not 'see' us, and do not acknowledge us. We are not part of the fictional work, but mere observers of it. In pro-wrestling, however, things are very different. We are not an unacknowledged audience sitting quietly behind an imaginary wall - we are actually part of the performance. We play the role of spectators both within, and without, the fiction. Tim Kail, a pro-wrestling critic, has described this fictional set-up, aptly I think, as 'no-wall theatre' (Kail: 2017):

Pro-wrestling has no walls to begin with. It is "no-wall-theater" [sic] - a category of performance art that strives to mimic reality so thoroughly that it removes all appearance of artifice.

It may seem striking that this description can hold, given what we've said about the exaggerated spectacular nature of the storytelling in pro-wrestling. Such spectacle surely screams artifice, and yet here we have talk of the removal of artifice and the thorough mimicking of reality. It seems that this should constitute a major tension, yet somehow pro-wrestling manages to be both artfully artificial and also adept at getting us to play along with its fundamental kayfabe conceit that the inring theatrics are real, legitimate.

To understand how this is possible, we would do well to help ourselves to one of the most influential of recent theories of fiction and representational art, namely Kendall Walton's theory of make-believe (Walton: 1990). Walton holds that whenever we engage with representational works - be they paintings, novels, films or plays - we are playing games of make-believe. ${ }^{9}$ These games are exercises of the imagination, involving props. The props are the real objects (the paintings, the words of the novels, the performances within the film or play) that serve to prompt 
our imaginings, and often also play the role of being the objects of our imaginings. They also generate fictional truths within the game of make-believe.

Walton introduces his theory using the example of 'ordinary' games of make-believe played by children, which he sees as being on a continuum with the games prompted by representational works. Children might play a game in which they imagine tree-stumps in the woods to be bears - the tree stumps are the props that prompt the imaginings, and also form the objects or contents of the children's acts of imagining. When a tree-stump is discovered, it becomes part of the game of make-believe that there is a bear in that place; or, to put it another way, it becomes fictional that there is a bear. This is what is meant by the claim that props generate fictional truths. As such, props constrain what kinds of imaginings are legitimate in the game of make-believe (the children are mandated to imagine bears where there are stumps, but only where there are stumps - not where there are bushes, say).

The tree-stumps in the children's game are ad-hoc props - they are chosen by the children to act as generators of fictional bear-truths on the basis of a shared convention ('let's pretend the stumps are bears'). But other games of make-believe are prompted by props that are designed or created by someone precisely for this purpose. For Walton, representational works are such props. Paintings, statues, plays and novels are made specifically for the purpose of functioning as props in audiences' games of make-believe - this is in fact what makes them all representational works. They prompt imaginings, act as objects of imaginings, and generate fictional truths in our games.

We can therefore see how pro-wrestling events can also count as representational works in Walton's sense. For one thing, they involve a variety of very effective props that encourage the audience to enter into the game of makebelieve that we have hitherto referred to as the kayfabe. Kail (2017) puts it thus:

The ring, the fact that the performers are called wrestlers, the presence of commentators, and the setting all exist to reinforce the illusion that the audience is witnessing what those things say: a fight.

But there is more to our immersion in pro-wrestling than just the effect of the verisimilitudinous nature of the designed props. Another important aspect of Walton's theory, which helps us further to understand this, is that in our games of 
make-believe some of the most important objects of our imaginings are ourselves. As we participate in our games, guided by the features of the representations with which we are playing, we typically engage in some kinds of de se imaginings perhaps imagining of ourselves when viewing a painting that we are seeing the people depicted in a painting strolling by, or when reading a novel that we are reading the report of some character in the novel, or some person who knows of the events in the novel. These de se imaginings generate fictional truths about ourselves. Thus, we become reflexive props in the games of make-believe (Walton: 1990, 59, and 209-239).

This idea, that when we engage with representations we engage in imaginings about ourselves, has often seemed implausible when considered in the context of some kinds of representations. The suggestion that viewing paintings gives rise to de se imaginings, for instance, can seem a bit of a stretch. And while some novels lend themselves easily to imaginings about ourselves reading 'real' reports - novels in journal-style, or epistolary novels, for instance - not all novels or literary representational works do this. But the case of pro-wrestling is one where the idea that we ourselves are reflexive props seems utterly plausible, since it in fact accords very well with the 'no-wall theatre' phenomenon adverted to earlier. It captures the fact that, whether in the wrestling hall or arena, or watching at home on television, the role played by the audience is a dual one: we are both the audience-of-the-fictional-phenomenon-of-pro-wrestling, and, fictionally, audienceof-the-real-combative-competition unfolding before us.

Moreover, pro-wrestling constitutes a theoretically interesting anomaly for Walton's account in this respect. Walton holds that when we play our games of make-believe with representations, the fictional truths generated by our de se imaginings constitute what he calls the 'game world'. But this is not the only 'world' in play. The representations themselves also give rise to another world of fictional truths - the 'work world'. The game world and the work world are not the same thing and should not be confused, since (i) there are multiple game worlds for each representational work (that is, there are multiple games of make believe engendered by it since there are multiple 'gamers'), but there is only one work world; and (ii) the game world contains fictional propositions about the person 
playing the game, but these propositions are not part of the work world. However, as we shall see, it is possible that pro-wrestling problematizes this distinction.

When we engage in the make-believe prompted by pro-wrestling, we generate fictional truths about ourselves, such as that we are at a real sports event, watching a real sporting contest. This, in Walton's terminology, is part of the game world. And, in Walton's terminology, this kind of content does not belong to the work world - after all, with regular fictional representations, it is not the case that I, the viewer or reader, am part of the work world. But when I am the audience of a pro-wrestling representation, it is not only a fictional truth of the game world that I am there, as a genuine-sports watcher; it is also part of the work world that I and all the other spectators are there - it is part of the fictional representation of prowrestling that there is an audience watching, and that the wrestlers are interacting with this audience - provoking them, reacting to them, getting them on-side, and so on. Unlike with regular theatre, here the fictional representation extends beyond the stage - or ring, in this case - and spreads out through the whole arena, encompassing the audience. ${ }^{10}$ The audience is really there watching the performance and interacting with the wrestler-actors, but we are also fictionally there watching wrestlers engage in genuine combat. As Kail (2017) puts it:

Imagine a play that's taking place not on a stage, but in the actual location described in the script, and the audience are simultaneously characters in the 'play' they're observing (they are the fight's audience).

That's No-Wall-Theater [sic] and that's what pro-wrestling is doing.

Pro-wrestling, then, may be unusual among fictional representations, in that it blurs the borders between work world and game world (in Walton's terminology), and offers us an experience of 'no-wall-theatre' (in Kail's terminology). As a fiction, it invites a game of make-believe that unfolds not just 'in our heads' but in front of and all around us; a game that is also shared with other game-players in the moment, and that provides a rare opportunity for near-total immersion, in which the audience is enabled 'to suspend their disbelief and arrive at a place of catharsis or ... "The Moment of Pop"' (Kail, 2017).

This relatively rare depth of immersive experience is one of the valuable benefits to be had from engaging with pro-wrestling. But I also claimed that, as well 
as being arguably more immersive than other fictional representation, pro-wrestling is also arguably more interactive. By 'interactive' is meant both the ability to interact physically with the world of the representation, and the power to modify it. $^{11}$

We have already seen that pro-wrestling is highly audience-interactive indeed, to the extent that the audience even becomes part of the fiction. At the most simple level, in the arena, this interaction is manifested in the vocal encouragement (and rejection) offered by the so-called 'WWE universe' (i.e. the fans) at the events. Fans cheer, boo, chant, and hold up homemade signs that express their thoughts and feelings about the in-ring characters. The wrestlers, in return, play up to the audience, encouraging the chants and cheers. Home audiences, meanwhile, aren't able to interact live in the same way, but will nonetheless react in an immediate way to the antics in the ring. This basic fan response is one level of interaction with the world of the representation.

But the interaction and appreciation also goes further than this, extending beyond the fiction. The fandom of pro-wrestling is an extremely active one, producing a plethora of discussions, criticism, and analyses of the events that take place in the ring. Most of this discussion nowadays occurs online, whether on dedicated wrestling discussion channels on YouTube, on discussion boards, blogs, and websites or on social media sites like Twitter and Tumblr. What is notable about this discussion and analysis is that it is not simply confined to discussing what (fictionally) happened in the ring, but also - perhaps predominantly - concerned with speculating from a meta-perspective about how things are, and how they'll develop.

Fans critically discuss the trajectories of characters (such as, whether the development of a character is being played out appropriately or not), the development of story arcs, and the potential strategies being employed by the creative writers on the show. In other words, they critique the scripting. This level of critical appreciation arguably lends pro-wrestling a more serious engagement aspect than does 'mere entertainment'. When critiquing the story of wrestling from outside of the fiction, the criticism fans are producing is similar to other forms of literary or pop culture criticism. We can, for instance, compare the meta-critical 
activity of the serious wrestling fan to that of the pop-culture critic who offers analyses of television dramas or soap-operas.

It is also possible that some of this criticism, carried out as it is through openaccess media, has an effect on the future of some wrestling stories - there is much speculation over the extent to which fan reaction, commentary, and criticism might be shaping the decisions made by the creatives over how stories are scripted. A recent example of this was the fans' backing of 'underdog' wrestler Daniel Bryan, an unlikely wrestling hero not destined for top-card greatness, who captured the audience's affection to such a degree that their vocal support went from being a chant, to a disruption, to an official storyline that ultimately resulted in Bryan becoming champion. ${ }^{12}$ While it is by no means a simple matter to know the extent to which this kind of fan-effect is really taking place, the possibility of it means there is a level of interactivity at work that is less common in most other fictional representations.

Whether or not it is being acted upon by the wrestling writers, it is fair to say that some of the critical activity of wrestling appreciators is carried out at a level comparable to the professional criticism engaged in by literary and film critics. It seeks to highlight the significant value to be had in appreciating the complex levels of engagement wrestling offers, from the sheer pop of enjoyment at the sight of a great move well executed, or the appearance of an anticipated wrestler onto the scene, through to the moments of cathartic satisfaction as a profound and deeply resonant moral theme reaches its climax, to the intellectual ponderings over the workings of this surprisingly intriguing fictional world.

Pro-wrestling, then, offers opportunities for both deep immersion in the work, via the fictional game of make-believe, and also for interaction between audience and work on multiple levels. That it can offer both is undoubtedly part of its appeal, and also part of what makes it unusual amongst fictions, since immersion and interactivity are features that are often in tension with one another. This is because interactivity at the more serious, critical, level involves an attention to the medium - the devices of the fictional representation - and a critical step back from the content of the representation itself; while immersion conversely requires a 'seeing-through' the medium and shift of attention away from one's actual situation 
and towards the representational content. ${ }^{13}$ It is generally uncommon, then, for fictional artforms to blend immersion and interactivity in quite the way that prowrestling does. ${ }^{14}$ When engaging with pro-wrestling, audiences essentially pop 'in and out' of the fiction as they watch, at one moment enjoying the action within the fiction, at another moment pulling outside of the fiction in order to reflect upon it. This reflection is itself then often fed back towards the work in the form of audience critique and commentary, or even just the vocal response at the events themselves. This traversing in and out of the fiction occurs more fluidly and naturally with prowrestling engagement than is normally the case when we engage with novels, theatre, or film, and is thus something that contributes to the unique nature of prowrestling within the realm of fictional representational works.

\section{What's Not To Love?}

I started out by asking what is going on when pro-wrestling fans engage with prowrestling - how they could seem to be so invested in the apparently 'fake' sports action they are witnessing. I have claimed that, to understand this, we need to understand pro-wrestling for what it is - principally, that it belongs firmly in the camp of fictional representational artforms, rather than the camp of genuine sport. Understood as a fictional representation, pro-wrestling can be shown to offer its audience a multitude of rewards and pleasures, from the basic appreciation of beautiful or impressive physical movement, to appreciation of dramatic themes and the emotional pleasures engendered by them, to the experience of deep immersion, and the opportunity for critical activity. At its core, it invites us into a game of makebelieve that makes us care about the characters and the drama within that makebelieve world, and it thrills us with the performances that are the medium of the representation. The question that now remains, then, is not what on earth are prowrestling fans enjoying?, but rather why on earth aren't you watching pro-wrestling?

\section{Notes}

${ }^{1}$ By 'pro-wrestling' is meant the marketed, commercial, spectator phenomenon of professional show-wrestling, the most well known version of which is probably the WWE (World Wrestling Entertainment) promotion. The WWE's product will be what 
I have in mind here, though it should be noted that there are many other promotions and that pro-wrestling exists, in more or less the same form, in numerous countries.

${ }^{2}$ For a quick verification of this, see the collection of images by the WWE of audience reactions to the moment when The Undertaker's legendary 21-year streak was brought to an end at WrestleMania 30 in 2014. See:

https://www.wwe.com/shows/wrestlemania/30/wwe-fans-react-to-undertakersstreak-ending-photos\#fid-26303024

3 I take it that for something to count as 'sport proper' (to be a 'real' sport) it must necessarily involve genuine competition; while we might occasionally use the term 'sport' as a catch-all term for various sporting activities (e.g. training, jogging, and such like) to class something as ' $a$ sport' requires that it be a rule-governed activity involving athletic or skilled competition.

${ }^{4}$ For instance, shows on the WWE network streaming service always open with a 'disclaimer' statement that the wrestlers are 'WWE characters' that are 'fictitious and do not reflect the personal lives of the actors portraying them'.

5 It must be noted that pro-wrestling is of course also a televised product, at the same time as being a live-arena product, and this duality of medium does imply two different kinds of audience experience. An analysis of the dual-product nature of pro-wrestling is of considerable interest in itself, but lies outside the scope of the present paper. In terms of the discussion in this section, the televised aspect does not rule out what is said here about the spectacular nature of pro-wrestling - the experience may be less communal when witnessed in the confines of one's own home, but the spectacle and its themes can still be tapped into.

${ }^{6}$ The essay is ostensibly about the world of Paris' wrestling halls in the 1950s, but is just as applicable to the pro-wrestling of today.

${ }^{7}$ A couple of examples illustrating this point: (i) gos wrestler and rebellious regularguy character Stone Cold Steve Austin's enduring battles against the villainous authority figure, Chairman Vince McMahon, resonated with the blue-collar workers in the audience used to having to deal with an unsympathetic boss, or to being at the mercy of 'The Man' - in terms of audience uptake, it was one of the all-time most successful feuds; (ii) after being betrayed by his former 'brother' Seth Rollins in perhaps the greatest heel-turn in WWE history, Dean Ambrose's next in-ring promo had him explicitly relating this feeling of betrayal to the audience members with the lines 'history is full of people like you, Seth; everyone in this building knows somebody like you, Seth - the kind of guy that would stab his brother in the back'. Monday Night Raw episode 1098 6/9/2014 [my emphasis]. The audience loudly concurred. ${ }^{8}$ Notwithstanding the existence of some avant-garde and postmodern theatre works that involve the audience - but these are generally the exception to the rule when it comes to the art form of theatre.

9 In fact, Walton (2015: 75-83) also thinks engagement with genuine sports is a matter of the spectators playing games of make-believe, too. This account best explains why sports fans get so emotionally caught up in the fortunes of 'their' team, or competitor, when - in the grand scheme of things - none of it really matters. But while competitive spectator sports may share something with entertainment and show business in this respect, Walton correctly maintains that 
such sports are 'not quite show business', for the key reason that they are more akin to natural objects than works of art. Despite being products of human activity, competitive sports games do not have anything like a controlling author overseeing the action for dramatic purposes, and the players' primary objective in their activity is to win the game or competition; any entertaining, show-like qualities are a byproduct of the players' competitive actions. This, again, is why pro-wrestling is a different kind of phenomenon to competitive sport.

${ }^{10}$ It actually spreads further, of course - out of the arena and into the homes of those watching on television. Those who watch the product on television are no less caught up in the game of make-believe, though their games are mediated somewhat differently; they are also part of the work world too, since it is part of the representation of pro-wrestling that the events are televised and watched by millions at home.

${ }^{11}$ For a discussion of interactivity and immersion, see Ryan (1994).

${ }^{12}$ As discussed by Ezell (2017).

13 See Ryan (1994, section 12): There is 'a relative transparency of the medium. The reader or spectator looks through the work toward the reference world'.

${ }_{14}$ One other kind of fictional medium in which we do see a high level of immersion and interactivity is, of course, video-gaming, and VR. See Ryan (1994). Engagement with this fictional medium is usually a more solitary experience, though.

\section{References}

Barthes, R. 1957. "The World of Wrestling." In Mythologies, 13-23. Paris: Editions du Seuil.

Ezell, J. 2017. "The dissipation of "heat": Changing role(s) of audience in professional wrestling in the United States." In Performance and Professional Wrestling, edited by B. Chow, E. Laine, and C. Warden, 9-16. London and New York: Routledge.

Grant, T. 2017. "The Aria of Babyface Cauliflower Brown." (Film essay). New York Times, July 11, 2017 (accessed 5 October 2018)

https://www.nytimes.com/2017/07/11/opinion/babyface-cauliflower-brownwrestling.html

Kail, T. 2017. "Pro-Wrestling is an Art ... But It's Better When Wrestlers Don't Know That." The Work of Wrestling. (Website) July 20, 2017 (accessed 5 December 2017) http://www.workofwrestling.com/workblog/pro-wrestling-is-an-art-but-its-betterwhen-wrestlers-dont-know-that

Ryan, M-L. 1994. "Immersion vs. Interactivity: Virtual Reality and Literary Theory." Postmodern Culture 5 (1). Johns Hopkins University Press. Retrieved November 10, 2018, from Project MUSE database.

Walton, K. L. 1990. Mimesis as Make-Believe: On the Foundations of the Representational Arts. Cambridge, Mass.: Harvard University Press.

Walton, K. L. 2015. "'It's Only a Game!': Sports as Fiction." In In Other Shoes, 75-83. Oxford: Oxford University Press. 
Lisa Jones

University of St Andrews

St Andrews

$\mathrm{KY} 16$ gAL

Lj14@st-andrews.ac.uk 